\title{
Modification of the rotating model method for studying the sexual discriminative abilities of butterflies (Lepidoptera)
}

\author{
TsUYoshi TAKEUCHI
}

Entomological Laboratory, Graduate School of Life and Environmental Science, Osaka Prefecture University, Gakuencho1-1, Nakaku, Sakai 5998531, Japan; e-mail: takeuchiozephyrus@yahoo.co.jp

Key words. Lepidoptera, butterflies, mating behaviour, sexual recognition, territory, wing colour, rotating wing model

\begin{abstract}
Recently, Imafuku \& Kitamura (Eur. J. Entomol. 112, 2015: 328-333) succeeded in inducing males of two territorial butterflies, Chrysozephyrus smaragdinus and Neozephyrus japonicus, to respond to wing models by rotating the models. Based on the results of two-choice tests in which males stayed longer within $50 \mathrm{~mm}$ of the female model than the male model the authors claim that males of both of these butterflies identify females using the patterns on the wings. I think this study provides a new method for studying the discriminative abilities of butterflies. In contrast to static models, however, butterflies attracted to rotating models do not land on the models but remain at some distance from the moving models. A close approach to a model, therefore, does not always reflect the animal's preference. I suggest a better way of using this method for testing the discriminative ability of butterflies.
\end{abstract}

The conspicuous colour of butterfly wings is generally thought to be used for intraspecific communication, especially in mate location. Male butterflies exhibit two types of mate locating behaviour: patrolling and territorial (Rutowski, 1991). Patrolling males fly continuously in search of females, whereas territorial males occupy lookout points and fly off and intercept passing females. Using static butterfly models, researchers have revealed that males of some species discriminate the sexes of conspecifics based on wing colour (Obara, 1970; Rutowski, 1977; Silberglied \& Taylor, 1978), whereas males of other species do not (Wago et al., 1976; Yamashita, 1995; Rutowski \& Rajyaguru, 2013).

An important bias in these studies is that the target butterflies are generally patrolling species. The sexual discrimination of territorial species has seldom been studied. Perhaps this is because males of territorial species rarely respond to static wing models, which makes studies of sexual discrimination difficult. On the other hand, it is known that males of territorial species respond to almost all moving objects of proper size. For example, Tinbergen et al. (1972) succeeded in inducing males of the grayling, Eumenis smele, to fly towards moving circular or rectangular boards. Similar results are reported for other territorial butterflies such as Asterocampa leilia (Rutowski et al., 2001), and Pararge aegeria (Bergman et al., 2009). These results indicate that males of territorial species are unable to discriminate not only the sex but also the species of flying objects at first sight. However, they may identify flying objects at a short distance, because territorial males chase conspecifics longer than heterospecifics (e.g., Suzuki, 1976; Lederhouse, 1982; Lederhouse et al., 1992; Fischer \& Fiedler, 2001). Currently, however, there is practically no evidence that males of territorial butterflies use wing colour to identify females.

Recently, Imafuku \& Kitamura (2015) claimed that males of the territorial butterflies, Chrysozephyrus smaragdinus and Neozephyrus japonicus identify females by the colour of their wings. Males of both species have brilliant green dorsal wing surfaces whereas females have dark dorsal wing surfaces. The authors succeeded in inducing males to respond to wing models by rotating the models using motors (rotation rate: $12.1 \pm 3.2 / \mathrm{s}$ ). They presented models of the wings of a male and a female simultaneously to a territorial male, and recorded which model the male preferred. They carried out sets of two trials on C. smaragdinus (changing the position of both models), and sets of four trials on $N$. japonicus (changing the position and the direction of rotation of both models). Preference for each model was evaluated using two criteria. (1) The model the males first approached to within $50 \mathrm{~mm}$ of its center, and (2) How long males stayed (flew) within $50 \mathrm{~mm}$ of the center of each wing model. Each trial was terminated when the male flew away from the apparatus. The results indicate that males approached both models equally but stayed longer at the female model. Based on these results the authors conclude that males could not discriminate the sex of the wing models at first sight; however, they could discriminate the sex of the wing models (and preferred the female wing model) when close to the model. The authors also tested the male preference for two types of female wings in $N$. japonicus. I think this study provides a new way of studying the discriminative abilities of butterflies. As is often the case when using a new method, however, there are a few problems. In the present paper, I identify these problems and suggest a better way of using this method. I do not refer here to experiments using two types of female wings, because the problems with such experiments are practically the same as those with experiments on sexual discrimination.

Firstly, there was almost no description of how the male butterflies responded to the wing models. The authors only refer to the first approach and the time they stay within $50 \mathrm{~mm}$ of each model. Therefore, readers do not know how the butterflies behaved other than when they were within $50 \mathrm{~mm}$ of each model. In addition, the authors only provide the mean difference (and SE) in the time for which they stayed close to the two wing models. They do not provide the time they stayed close to each model, which would give an indication of the attractiveness of the wing models to territorial males. In the case of $C$. smaragdinus, males stayed ca. $0.6 \mathrm{~s}$ longer at the female model than the male model (Fig. 2A in Imafuku \& Kitamura, 2015). Considering that this difference is the sum of two trials, the mean difference in staying time in one trial was ca. $0.3 \mathrm{~s}$. In the case of $N$. japonicus, males stayed ca. 1.1 $\mathrm{s}$ longer at the female model than the male model (Fig. 2B in Imafuku \& Kitamura, 2015). Considering that this difference is the sum of four trials, the mean difference in staying time in one trial was ca. $0.275 \mathrm{~s}$. I wonder whether such slight differences really 
indicate that males could discriminate the sex of the wing models. It is more likely that these results indicate that males could not effectively discriminate the sex of the wing models.

A more important problem is whether staying within $50 \mathrm{~mm}$ of the center of the wing model is a valid indication of preference. The authors do not give reason for adopting $50 \mathrm{~mm}$. The forewing length of both species is ca. $21 \mathrm{~mm}$ (Shirôzu, 2006; Takeuchi, 2006), which means that, if the criterion of $50 \mathrm{~mm}$ is adopted, the tip of the rotating model is within less than $30 \mathrm{~mm}$ of an approaching male whose forewing length is ca. $21 \mathrm{~mm}$. I think this is too short. When one conducts a choice test using static models or food, the criterion of $50 \mathrm{~mm}$ may be valid because animals can land on the preferred objects (e.g., Obara, 1970; Wago et al., 1976; Yamashita, 1995; Rutowski \& Rajyaguru, 2013). However, the authors carried out a two-choice test using rotating models (butterfly wings attached to a $0.3 \mathrm{~mm}$ plastic plate). Although the authors do not describe how close males approach wing models, it is clear that in most cases males did not touch the model because if they had they would have been flicked off and the experiment would have failed. (Imafuku confirmed that males rarely touched the models). That is, males attracted to rotating models should keep some distance from the models in order to avoid being struck by the moving model. Consequently, the criterion of 50 $\mathrm{mm}$ (in practice less than $30 \mathrm{~mm}$ ) as an indication of preference is very arbitrary. Males might stay further away from a male than a female model not because they prefer the female model but because they recognize the edge of the wing of a male model from further away than that of a female model because the colour of male wings is more conspicuous. The diameter of naturally occurring male-male circling flights of C. smaragdinus is about 100 $\mathrm{mm}$, which is twice $50 \mathrm{~mm}$ (Imafuku \& Ohtani, 2006).

I think part of the reason why these authors define staying (preference) as flying within $50 \mathrm{~mm}$ of the wing model is that the models of both sexes were located only $290 \mathrm{~mm}$ apart. From common sense, this distance is a swaying range of a flying butterfly that cannot hover (Brodsky, 1994), and therefore it is difficult to determine to which models males are attracted.

I think the rotating model methd used by Imafuku \& Kitamura (2015) is excellent but there is a better way of using their method. That is, researchers should not present models of both sexes simultaneously, but rather present either a male or a female model. Territorial males will be attracted to the model and then lose interest and return to their perching point. Researchers should record the rate and duration of a male's response to a model. This would not require the arbitrary definition of within $50 \mathrm{~mm}$ of the model as an indication of male preference. Ideally, sexual discrimination should be judged based not on the duration of the approach but whether the model induces mating behaviour (e.g., Wago et al., 1976; Yamashita, 1995). Unfortunately, flying females (rotating models) do not induce male butterflies of many species to exhibit typical courtship behaviour. If researchers can let the males attracted to a rotating model exhibit mating behaviour (for example, by stopping the motor), this will provide much clearer information.

\section{REFERENCES}

Bergman M. \& WikLund C. 2009: Visual mate detection and mate flight pursuit in relation to sunspot size in a woodland territorial butterfly. - Anim. Behav. 78: 17-23.

Brodsky A.K. 1994: The Evolution of Insect Flight. Oxford University Press, New York, 244 pp.
FISCHER K. \& FIEDLER K. 2001: Resource-based territoriality in the butterfly Lycaena hippothoe and environmentally induced behavioural shifts. - Anim. Behav. 61: 723-732.

IMAFUKU M. \& KiTAMURA T. 2015: Ability of males of two theclini species (Lepidoptera: Lycaenidae) to discriminate between sexes and different types of females based on the colour of their wings. - Eur. J. Entomol. 112: 328-333.

IMAFUKU M. \& OHTANi T. 2006: Analysis of coordinated circling and linear flights of a lycaenid butterfly species. - Naturwissenschaften 93: 131-135.

Lederhouse R.C. 1982: Territorial defense and lek behavior of the black swallowtail butterfly, Papilio polyxenes. - Behav. Ecol. Sociobiol. 10: 109-118.

Lederhouse R.C., Codella S.G., Grossmueller D.W. \& MacCARONE A.D. 1992: Host plant-based territoriality in the white peacock butterfly, Anartia jatrophae (Lepidoptera: Nymphalidae) - J. Insect Behav. 5: 721-728.

OBARA Y. 1970: Studies on the mating behavior of the white cabbage butterfly, Pieris rapae crucivora Boisduval III. Near-ultra-violet reflection as the signal of intraspecific communication. - Z. Vergl. Physiol. 69: 99-116.

RUTOWski R.L. 1977: The use of visual cues in sexual and species discrimination by males of the small sulphur butterfly Eurema lisa (Lepidoptera, Pieridae). — J. Comp. Physiol. 115: 61-74.

Rutowski R.L. 1991: The evolution of male mate-locating behavior in butterflies. - Am. Nat. 138: 1121-1139.

Rutowski R.L., Mccoy L. \& Demlong M.J. 2001: Visual mate detection in a territorial male butterfly (Asterocampa leilia): effects of distance and perch location. - Behaviour 138: 31-43.

Rutowski R.L. \& RaJyaguru P.K. 2013: Male-specific iridescent coloration in the pipevine swallowtail (Battus philenor) is used in mate choice by females but not sexual discrimination by males. - J. Insect Behav. 26: 200-211.

SHIRÔZU T. 2006: The Standard of Butterflies in Japan. Gakken, Tokyo, 336 pp. [in Japanese].

Silberglied R.E. \& TAYLOR O.R.J. 1978: Ultraviolet reflection and its behavioral role in the courtship of the sulfur butterflies Colias eurytheme and C. philodice (Lepidoptera, Pieridae). Behav. Ecol. Sociobiol. 3: 203-243.

SUZUKI Y. 1976: So-called territorial behaviour of the small copper, Lycaena phlaeas daimio Seitz (Lepidoptera, Lycaenidae). - Kontyû 44: 193-204.

TAKEUCHI T. 2006: The effect of morphology and physiology on butterfly territoriality. — Behaviour 143: 393-403.

Tinbergen N., Meeuse B.J.D., Boerema L.K. \& Varossieau W. 1972: The courtship of the grayling Eumenis (= Satyrus) semele. In Tinbergen N. (ed.): The Animal in its World. Allen \& Unwin, London, pp. 197-249.

Wago H., Unno K. \& SuzuKi Y. 1976: Studies on the mating behavior of the pale grass blue, Zizeeria maha argia (Lepidoptera: Lycaenidae) I. Recognition of conspecific individuals by flying males. - Appl. Entomol. Zool. 11: 302-311.

YAMASHITA K. 1995: Comparison of visual cues in mating behavior of four species of swallowtail butterflies. In Scriber J.M., Tsubaki Y. \& Lederhouse R.C. (eds): Swallowtail Butterflies: Their Ecology and Evolutionary Biology. Scientific Publishers, Gainesville, FL, pp. 133-144.

Received March 30, 2015; revised and accepted May 22, 2015 Prepublished online July 10, 2015 